\title{
Landmark global tobacco treaty coming into effect
}

The Canada-inspired global treaty to reduce tobacco sales and use comes into effect Feb. 28.

Canada sponsored the original resolution in 1995 that led to the development of the WHO Framework Convention on Tobacco Control, the world's first international health treaty.

In addition, Canada's tobacco control strategies were a template for many of the measures, said Cynthia Callard, executive director of Physicians for a Smoke-free Canada. "Canada was a big champion of the treaty financially and morally."

The treaty, which is legally binding, bans tobacco advertising and promotion unless constitutional barriers exist and requires warning labels that cover $30 \%$ of cigarette packages.

It also provides nations with a roadmap for enacting researchbased policies in areas such as secondhand smoke protections, tobacco taxation, tobacco product regulation, combatting cigarette smuggling, public education, and tobacco cessation treatment.
Given that the treaty touches on many legislative areas, including taxation, advertising, education, law and health, it is "quite astounding" that it passed, said Carla Gilders, the director general of Health Canada's International Affairs Directorate.

The treaty was agreed on by WHO's 192 member states in 2003, but wasn't slated to come into effect until 90 days after being ratified by 40 countries. Peru became the 40th on Nov. 30. The US has not yet ratified the treaty despite pressure from lobby groups such as the American Lung Association.

The ratifying countries - 49 as of mid-January - will be part of the Conference of Parties, which will decide how to manage, monitor and finance the treaty, which is binding.

Canada is already in "substantial compliance because much of the treaty was modelled on Canadian legislation," said Gilders. In addition to taking part in the conference, Canada will share its

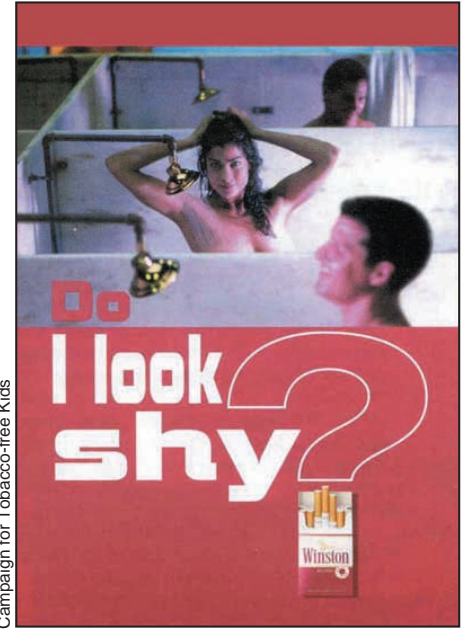

What's being sold here? The treaty includes new tobacco advertising guidelines.

expertise. There is $\$ 1$ million in the Tobacco Control Strategy fund for international projects.

Diseases related to tobacco use kill nearly 5 million people worldwide every year. About $84 \%$ of smokers live in developing countries, where the tobacco epidemic is still growing. Barbara Sibbald, CMAJ

\section{New Technology}

\section{Private-public partnerships planned for BioMed City}

Leading medical microbiologists and biomedical entrepreneurs are teaming up in Winnipeg to create "BioMed City," dedicated to studying and fighting infectious diseases.

The catalyst for BioMed City is the International Centre for Infectious Diseases (ICID), a not-for-profit private agency that will build private-public partnerships to raise money for training, research and commercialization. The federal govern+ ment has invested $\$ 3$ million to bring ICID to life.

Winnipeg is "already a Mecca for research in infectious diseases," ICID president and CEO Terry Duguid says. "We want to build on what we have."

Winnipeg's biomedical sector includes the Canadian Public Health Agency and the Canadian Science Centre for Human and Animal Health. These 2 are aligned with the University of Manitoba's department of medical microbiology, where researchers garnered international headlines for identifying a group of HIV-resistant prostitutes in Nairobi. A promising HIV vaccine initiative in partnership with Oxford University is now underway. $U$ of $M$ scientists have also received \$23 million from the Gates Foundation to expand an HIV prevention model.

ICID will focus on raising funds for research into new vaccines, biomedical devices, systems of prevention and biosafety. Profits from commercial endeavours will be used to fund additional research.

ICID has an all-star board, including Dr. Stephen Moses, $\mathrm{U}$ of $\mathrm{M}$ researcher; Dr. Frank Plummer, director of the $\mathrm{Na}$ tional Microbiology Laboratories; Dr. John Langstaff, president of Winnipeg-based Cangene Corporation; and Dr. Lorne Babiuk, head of the University Saskatchewan's Vaccines for Infectious Diseases Organization.

"Throughout the world, there are groups just concerned with commercialization and groups just concerned with research," said Board Chairman Moses. "We think there is a great value in bringing these groups together." - Dan Lett, Winnipeg 